Western University

Scholarship@Western

Western Libraries Publications

Western Libraries

$4-2012$

Dungeons and Downloads: Collecting Tabletop Fantasy Role-Playing Games in the Age of Downloadable PDFs

Dan Sich

University of Western Ontario, dsich2@uwo.ca

Follow this and additional works at: https://ir.lib.uwo.ca/wlpub

Part of the Library and Information Science Commons

Citation of this paper:

Dan Sich, (2012) "Dungeons and downloads: collecting tabletop fantasy role-playing games in the age of downloadable PDFs", Collection Building, Vol. 31 Iss: 2, pp.60 - 65 


\section{Dungeons \& downloads: collecting tabletop fantasy role-playing games in the age of downloadable PDFs}

Dan Sich

The D.B. Weldon Library, The University of Western Ontario, London, Canada

\section{Introduction}

Role-playing games (RPGs) are games of collaborative, improvised storytelling. Players assume the roles of characters while the referee controls all other aspects of the game. When played with an emphasis on role-playing, tabletop RPGs necessitate cooperation, imagination, interaction and spontaneity, and help develop skills such as acting, storytelling and problem-solving. The social and open-ended storytelling aspects of tabletop RPGs are their greatest appeal. Libraries that support games, social events, story-telling or theatre, should consider adding tabletop RPGs to their programming and collections.

Many fantasy (sword and sorcery) RPGs were originally inspired by the works of authors such as J.R.R. Tolkien, Robert E. Howard, H.P. Lovecraft and Fritz Leiber. As such, they provide a gateway to some fine fantasy literature and 'weird fiction'. Libraries are wellpositioned to support role-playing gaming in their communities with programming in the form of gaming groups and events, space in the form of group study rooms, and materials in the form of collections (e.g., rulebooks). Tabletop RPGs can easily be added to a library's programming and collection, whether or not the library or community has established gaming groups.

Today a rather dizzying array of RPGs exists, varying in popularity, price and ease of play. RPG publications contain rules for play and supplementary details. A WorldCat search reveals that many libraries have these publications in their circulating collections already. However, little has been published providing advice on selecting a game or developing a collection in support of that game. Publications can number anywhere from one to more than one hundred per game. For RPGs with a large published output, it can be difficult to identify the publications that are essential acquisitions.

My game-by-game examination of the innovative and sometimes opportunistic publication and sales models currently in place will reveal some novel methods used by RPG publishers to handle copyright, open access, peer-review, sales and distribution. Many genres of RPGs exist, including fantasy, science fiction and horror. This article will focus on major games from the fantasy genre. I will provide reasons for choosing or avoiding each game, highlight the essential rulebooks, and warn of any pitfalls. Understanding RPGs' publication and sales models can prove immensely helpful to libraries wishing to provide support for these unique collections, in terms of allocating both collections budgets and staff time, and in terms of developing programming to attract new users to the library.

\section{Literature review}

The literature includes several articles and one book chapter about RPGs and libraries. Most of the literature provides introductory information on RPGs and advice on programming -- 
there is little published on collections aspects of RPGs.

Excellent introductions to RPGs within the context of libraries are provided by Snow (2008), Danforth (2009) and Nicholson (2010). Snow also discusses RPG theory and classification, including the difference between 'rules-intensive' and 'rules-light' games, and notes that "The amount of rules in RPGs is nearly impossible to memorize and reference to the books is an inevitable part of playing these games" (Snow 2008). This certainly applies to most published RPGs, which tend to be 'rules-intensive'.

There are many RPGs available in the fantasy genre alone. The literature includes an overview of some of the more popular RPGs currently available and details on the differences between various editions of these games (Snow 2008), as well as advice on matching RPGs to specific patron age groups (Nicholson 2010).

Tips on adding RPGs to library programming (Snow 2009) and justification and strategies for hosting RPG programming in the library (Nicholson 2010) are provided in the literature. RPGs can help build "important life skills" (Snow 2009) and "spur further use of the collection" (Snow 2008). RPG programming requires staff time to run (Nicholson 2010) and a Game Master (or referee); this may be a role that a librarian can fill (Danforth 2009). Ian McKinney's IARPG/Azor Lok project [1] is an example case (Danforth 2009). Readers looking for compelling reasons or methods for including RPGs in library programming need look no further than these articles. It follows that such libraries should also include RPG publications in their collections, since not all patrons (especially youth) can afford their own copies of such publications.

Venues for purchasing RPG publications mentioned in the literature include gaming stores, publishers and online stores (Snow 2008), PDF purchase (Nicholson 2010), free downloads and print-on-demand via Lulu.com (Snow 2009, Nicholson 2010).

Nowhere in the literature is there mention of the myriad of RPG publication and distribution models currently in place. No one has discussed possible copyright restrictions on sharing purchased RPG PDFs. An examination of the output of certain RPG publishers will show a tendency to produce increasingly expensive and 'rules-intensive' RPGs, but no one has offered libraries recommendations or guidelines with respect to such games. These important, collections-related aspects of RPGs will be addressed by this article.

\section{The RPG publishing landscape}

Print RPG publications come in a wide range of formats including hardcover and softcover, and a wide range of bindings. In a library collection, any such volume can be catalogued, shelved and circulated. Some RPG publications come as boxed sets that include not only books but also gaming pieces such as dice, cards or counters that can easily be misplaced. Such pieces may require special treatment such as keeping them behind the circulation desk, so that library staff can ensure the completeness of the set, much as they might do with a set of chess pieces. Electronic RPG publications tend to be PDFs.

Publishers of best-selling RPGs tend to be prolific, producing numerous rulebooks, adventures and supplements. Each additional publication makes an RPG more complex or rules-intensive. Often the number of rulebooks that publishers define as 'core' increases as the number of rulebooks published increases. When marketing their publications, successful RPG companies imply that their game cannot be fully enjoyed without these publications. They may even offer subscriptions to facilitate purchase of serialized publications. 
Competition among RPGs is fierce, and some RPG publishers now provide 'open licensing' for certain aspects of their games in order to encourage third party publishers to produce compatible 'support' products.

When a game (or new edition of a game) is released it typically consists of one to three rule books, containing information for players, information for referees, and information about opponents. These initial publications are the only essential components to the game.

Additional rulebooks, supplements and adventures may be helpful but are optional. Good players can use their imagination to create characters, settings, plots and rules that are just as enjoyable. In addition, there are free or inexpensive alternatives to 'prolific publisher RPGs' . A new edition of an RPG is often an indication that the publisher has exhausted all ideas for new publications, or that the market has become saturated with content from the previous edition. New editions often repackage and re-sell material from previous editions. Changes between editions may create incompatibilities or necessitate 'conversion' between editions, and encourage players to purchase the newer publications.

Awareness of such publishing tendencies can help libraries save collections funds. It is not necessary to update to the latest edition of an RPG if the current edition is 'good enough' for, or even preferred by, the library's staff and its patrons. It's also worth considering how much has been invested in the current edition. If the library is not relying on the publisher to continue to generate new additional rulebooks, supplements or adventures, then the current edition need never be replaced. On the other hand, if the library is encountering difficulty in acquiring copies of essential, out-of-print rulebooks, if additional published adventures are desirable but not forthcoming, or if patrons are demanding the latest release, then it is most likely time to update to a newer edition.

Peer-to-peer, online, file-sharing programs have enabled the wide-spread and illegal sharing of RPG book content scanned and rendered as PDFs. The proliferation of these copyrightviolating PDFs is a threat to RPG publishers. To minimize the effects of PDF piracy, many RPG publishers offer a legal alternative in the form of purchasable PDFs. Some RPG PDFs bear a watermark that include the purchaser's name and date of purchase, in order to discourage illegal sharing. Some publishers have overhauled game mechanics and have incorporated game components such as cards and 'tokens'; these non-book components can be considered 'anti-piracy' measures, as they cannot be scanned and rendered as PDFs and thus shared. Thoughout this article, various purchasable PDF publications will be mentioned. Libraries should assume that purchasable RPG PDFs are licensed for single users, unless they can determine otherwise. For example, the publisher Paizo (see Pathfinder RPG below) states that users "may print one copy of any Paizo PDF for personal use." [2] This implies that libraries can not share any purchased PDFs with patrons. Similarly, Mythmere Games states that "customers are authorized to print physical copies of the pdf files for their own use." [3] The best option for libraries is to use free PDFs and/or to purchase print RPG books, and to avoid purchasing PDFs. An exception may be PDF material that is purchased for use only by the librarian running the RPG program; these should not be made availalble to patrons. Free PDFs, wherever they reside on the web, can be linked to from a library webpage related to RPG programming or gaming programming in general.

Unless otherwise stated, the purchase of standard 'polyhedral' dice (dice with 4, 6, 8, 10, 12 and 20 sides) is required to play the RPGs described below. Two 10-sided and several 6sided dice are useful. These can be readily obtained from a gaming store or from an online retailer. 


\section{The games and their publication models}

The following is a game-by-game examination of the publication and sales models currently in use by major fantasy RPGs. I will provide reasons for choosing or avoiding each game, identify rulebooks essential to the playing of each game, discuss quantity of rules and availability of publications, identify support-related factors (such as popularity, compatibility, existence of support communities), and highlight any novel methods of handling copyright, sales and distribution. Readers are encouraged to apply these criteria in examining any RPGs not discussed in this article.

To attempt to rate or rank these games would be highly subjective. A 'rules-light' game may be a perfect choice for one library, and a poor choice for another. Similarly, the existence of published support material may or may not be important for the library and its patrons. Just as there is no single best book for all readers, there is no single best fantasy RPG for all gamers. A library's choice(s), like those of its patrons, can and should be based on the needs and preferences of user groups. Casual discussion with users can help ensure that RPG collections match their interests.

\section{Dungeons \& Dragons}

Since its initial publication by Tactical Studies Rules (TSR) in 1974, Dungeons \& Dragons $(D \& D)$ has undergone many versions, editions and revisions. Three books are necessary to play the current, 'rules-intensive' 4th edition (4e): Player's Handbook, Dungeon Master's Guide and Monster Manual. The current publisher, Wizards of the Coast, is quite prolific, and many other optional rulebooks bearing similar titles (e.g., Player's Handbook 2) have been released. $D \& D$ remains the most popular fantasy RPG ever created, and libraries wishing to support $D \& D$ with collections have much to choose from. Purchasing all of the $D \& D$ rulebooks, sourcebooks and adventures available for a particular edition would prove rather expensive and is therefore inadvisable. $D \& D$ 's revised 3 rd edition (3.5e) and earlier, out-ofprint editions differ substantially from $4^{\text {th }}$ edition, and have been abandoned by Wizards of the Coast, but are still used by gamers. Used rulebooks can be obtained from online resellers. Watermarked PDF versions were once available for purchase from Paizo.com and DriveThruRPG.com, but this content was removed from these websites in April 2009 after Wizards of the Coast notified these companies that they could "no longer sell or distribute [Wizards of the Coast's] PDF products." [4]

Released by Wizards of the Coast in 2000, the Open Game License (OGL) [5] makes provisions for $D \& D$ game mechanics (methods of play) and descriptions of skills, spells, and monsters to be used by third party publications. A more restrictive Game System License (GSL) exists for $D \& D 4 \mathrm{e}$ [6]. However, from the perspective of U.S. Copyright Law, thirdparty $D \& D$-compatible publications (including alternative descriptions of $D \& D$ 's rules) are legal. [U.S.] "Copyright does not protect the idea for a game, its name or title, or the method or methods for playing it. ... Copyright protects only the particular manner of an author's expression in literary, artistic, or musical form." (U.S. Copyright Office) As such, the need for the OGL and GSL is questionable. Nevertheless, other gaming companies are putting the OGL to good use. One of the most noteworthy OGL-compliant publications is Pathfinder RPG. 


\section{Pathfinder RPG}

Paizo's Pathfinder RPG adopted, and has built upon, the game mechanics and conventions of $D \& D$ 3.5e, making it a popular and readily-available alternative to that out-of-print edition of $D \& D$. It is 'rules-intensive' and, as such, may be daunting to new players. The Core Rulebook contains everything required to play. Alternatively, the Pathfinder Roleplaying Game: Beginner Box includes a stripped-down version of the rules along with dice, gaming pieces and other components. The GameMastery Guide (referee's handbook), Advanced Player's Guide (additional rules), Bestiary (book of monsters) and many other books are also available. Errata are available for free download. Pathfinder's developers sought feedback in a massive, open beta play-testing, during which one could freely download the rules. This represented a benchmark in the RPG industry, and undoubtedly increased Paizo's fan (and customer) base. Gamers may subscribe to various serialized Pathfinder RPG publications (adventures, supplements) in print or PDF. Standing orders for Pathfinder RPG rule books are also available, so that subscribers receive every new rule book as it is released. As with $D \& D$, purchasing every Pathfinder RPG rulebook, adventure and supplement would prove expensive. Pathfinder RPG has its own Compatibility License (CL) [7] that allows third party publishers to create Pathfinder RPG-compatible publications. Many publishers have taken advantage of this, boding well for the future support of Pathfinder RPG.

\section{Retro-clones}

Some role-playing gamers prefer a 'retro' or 'rules-light' gaming experience, and may use out-of-print games or 'retro-clones' (essentially re-writes of out-of-print RPGs, usually $D \& D)$. Retro-clones have a similar look and feel to the games they emulate, but tend to be easier to use because they are clearer, more consistent and error-free compared to the original games. Most retro-clones offer free versions of their rules, and many full games are free or modestly priced, making them an ideal choice for libraries. Each $D \& D$-based retroclone offers a variation on a specific edition of $D \& D$, offering plenty of choice. A detailed list is available on the web [8]. Print copies of some retro-clones can be purchased via print-ondemand from Lulu.com. Retro-clones differ in the amount of support they have from other publishers. Below I will highlight two interesting options.

Microlite20 [9] is an extremely 'rules-light' $D \& D$ 3.5e-compatible game. It adopts the basic mechanics of D\&D 3.5e, but ignores the excessively detailed rules. The Microlite20 core rules are freely available on the web. They are incredibly short and demonstrate that RPG rules can be quite simple. Microlite20's supplements (Monster List, Spell List, Expert Rules) are similarly brief, modular (optional), and free to download [10]. Microlite20 is an ideal vehicle for libraries getting started with RPG programming, and for players who don't want to get bogged down in rules. Several other versions of Microlite are available [11]. Microlite74 is compatible with the Original 1974 edition of $D \& D$. Several free PDF versions are available from Lulu.com.

Dungeon Crawl Classics: Role Playing Game (DCC RPG) [12] (slated for release in January 2012) is a 'rules-light' game that is grounded in the same sword \& sorcery literature as 1974 's $D \& D$ (e.g., authors Robert E. Howard and Michael Moorcock) [13], making it a good choice for libraries hoping to connect RPGs to literature. A free beta version of the core rules will be available for download. DCC RPG will use both standard 'polyhedral' dice and 'Zocchi dice' (dice with 3, 5, 7, 14, 16 and 24 sides). Dungeon Crawl Classics is also a series of first, third and fourth edition $D \& D$-compatible adventures [14], available in PDF or print, and via subscription [15]. 


\section{Tunnels \& Trolls}

Tunnels \& Trolls first appeared in 1975 as an easy to learn, 'rules-light', highly-customizable alternative to $D \& D$. Tunnels $\&$ Trolls has changed very little over the years, and as a result it has a dedicated cult of followers. It uses only 6-sided dice. The designer encourages players to come up with their own rules, monsters, spells and adventures. The Tunnels \& Trolls revised 7 th edition ( $v 7.5$ ) boxed set contains the core rulebook and many extras (books of monsters, spells, solo and group adventures, dice) [16]. The Delver's Pack boxed expansion contains additional, non-essential content. Both boxed sets are printed by Fiery Dragon, and print copies can be purchased from a number of sources, including Paizo.com. PDF versions are sold by RPGNow.com and DriveThruRPG.com. Both sites also carry a free 'quickstart' version of the rules, which provides everything needed to play the game. Print, print-ondemand and/or PDF versions of new and out-of-print Tunnels and Trolls adventures are available from Paizo.com, RPGNow.com, DriveThruRPG.com, Lulu.com and Steve Jackson Games [17]. The free PDF fanzine TrollsZine provides supplementary information.

\section{RuneQuest and Basic Role-Playing}

Chaosium released RuneQuest in 1978, and Basic Role-Playing in 1980. Basic Role-Playing uses the core RuneQuest game mechanics, and its mechanics have in turn been used by many other Chaosium RPGs, notably Call of Cthulhu, Stormbringer and Elric!. Basic RolePlaying is an intuitive, 'rules-light' game that can be used in fantasy and other genres (such as horror). A free, PDF, 'light' version of Basic Role-Playing is available from Chaosium [18]. The current, 2008 version of Basic Role-Playing remains faithful to Chaosium's RuneQuest, and is available from Chaosium in print or PDF.

\section{'Mongoose' RuneQuest}

In 2006 Mongoose Publishing, holders of the rights to the name RuneQuest, re-wrote the RuneQuest rules in their own words and released their own game called RuneQuest, commonly referred to as "Mongoose RuneQuest". 'Mongoose' RuneQuest II (not to be mistaken with Chaosium's RuneQuest II) requires the Core Rulebook. Supplements include setting-specific source books based on the sword and sorcery literature of Michael Moorcock and Fritz Leiber. 'Mongoose' RuneQuest and RuneQuest II publications are available for purchase from DriveThruRPG.com and RPGNow.com, or in print from Paizo.com, and may be a good choice for libraries wanting to promote such literature.

\section{GURPS}

GURPS (Generic Universal RolePlaying System) [19], now in its 4th edition, is flexible enough to be used across multiple genres (such as fantasy, horror, military, Western). GURPS strives for realism, but does so at the cost of adding complexity to the rules. Two core rulebooks are available: Basic Set: Characters (for players) and Basic Set: Campaigns (for referees). PDF rulebooks and other supplements are sold by Steve Jackson Games. Warehouse 23 [20] sells print copies of these publications. GURPS Lite, a free version of the core 4th edition GURPS rules, is available for download [21] and provides everything required to play. GURPS rulebooks and supplements exist for the fantasy genre and many others, making cross-genre storylines possible. 


\section{Warhammer Fantasy Roleplay}

Warhammer Fantasy Roleplay: A Grim World of Perilous Adventure (WFRP), initially released in 1986, is a dark fantasy RPG now in its third edition (WFRP3). WFRP3 introduced complex game mechanics and additional game components. The large, expensive, core rules boxed set contains four books (also available as purchasable PDF from DriveThruRPG.com or RPGNow.com), several decks of cards, assorted cardboard pieces, and 'proprietary dice' (bearing symbols rather than numbers). These components serve a secondary function as anti-piracy measures. Other WFRP3 releases to date have followed the same boxed set model. Three recent WFRP3 hardbound rulebooks -- the Player's Guide, Game Master's Guide and The Creature Guide -- offer a component-free and more library-friendly alternative, and contain everything required to play the game other than the WFRP3 dice (available separately).

WFRP's first and second (WFRP2) editions are more 'rules-light' than WFRP3, and remain popular. A single core rulebook entitled Warhammer Fantasy Roleplay is all that is required to play each game, and these can easily be obtained through an online re-seller. WFRP2 PDFs can be purchased from DriveThruRPG.com and RPGNow.com. The Enemy Within fiveadventure campaign (for 1st edition) and the Paths of the Damned 3-adventure campaign (for WFRP2) are worth obtaining as they effectively establish the highly entertaining atmosphere of the WFRP world. Conversion between 1st and 2nd edition is relatively straight-forward. Unofficial, high-quality, fan-authored material is available for free from the websites Strike to Stun [22], Winds of Chaos [23] and Liber Fanatica [24].

\section{Other options, information sources and considerations}

Additional free RPGs can be found using The Free RPG Blog [25] and the Free RPG Directory [26]. As with other types of self-publication, some of these games may have quality issues due to lack of editorial review, while others are undoubtedly worth exploring.

It may be gratifying for a library staff member or patron to create their own RPG rules. Some familiarity with other RPGs will help. A quick look at Microlite74 or Tunnels \& Trolls shows that these needn't be complicated.

Weekly emailed newsletters from Paizo.com or FRPGames.com are an excellent means of keeping abreast of the latest RPG publications and publishing developments. Free RPG Day [27] is an annual promotional event held at gaming stores across North America. It's an ideal opportunity to learn about new and existing games. RPGGeek.com is an excellent resource for gamers' ratings and information on published RPGs [28].

A visit to the local gaming store can provide a sense of what RPGs and other types of games are being played in the community. Players of videogames, board games or Collectible Card Games (CCGs, such as Magic: The Gathering or Yu-Gi-Oh!) are sometimes exposed to RPGs in gaming stores or comic book stores but may never have had occasion to try playing them. Local RPG groups may provide information on the web, perhaps on forums or social media sites, regarding what games they are playing. These may provide opportunities for promoting the library's RPG program. 


\section{Recommendations and guidelines on choosing a game}

There are a number of factors libraries need to consider when selecting an RPG. 'Rules-light' games are inexpensive or free, while 'rules-intensive' games tend to get expensive due to the quantity of books presented as 'core' by the publisher. 'Rules-light' games are a better choice for newer and younger players, and for groups that prefer storyline over detailed rules. 'Rules-intensive' games have a steeper learning curve and, as such, tend to be a better choice for players and library staff with plenty of experience with RPGs, or who prefer a 'rules-intensive' gaming experience over storyline.

Using published adventures can also be expensive, require staff time for preparation, and may necessitate a certain degree of 'railroading' (that is, diverting of players' actions) in order to ensure that the players stay 'on track' with the published plotline. Developing one's own plotlines can but need not require as much preparation time as using a published adventure, leaves the storyline much more open-ended, and can be quite rewarding.

Some RPGs take themselves more seriously than others (though any RPG can be as humourous or as serious as the players desire). Tunnels \& Trolls and Warhammer Fantasy Roleplay include a fair bit of humour in their rules or published adventures. Dungeons \& Dragons and Pathfinder RPG, with their vast quantities of rules, tend to encourage a more reverent gaming experience.

Players may enjoy reading specific fantasy authors or series. Some games or adventures have tie-ins to fantasy literature (such as characters, locations or plots), but these elements can also be written-in to home-grown adventures. Either approach provides library staff with an opportunity to promote literacy and the use of library collections. Players may enjoy reading genres of fiction other than fantasy, such as horror or science fiction. These, and many other genres of fiction, are treated by RPGs not mentioned in this article. Systems like Basic Role-Playing and GURPS lend themselves nicely to any genre.

A good starting point for library staff new to RPGs is a 'rules-light' game with a free, downloadable version, such as Microlite74, Tunnels \& Trolls or Basic Role-Playing. While 'rules-light' systems leave a lot to the imagination or discretion of the referee, they also provide more opportunities for improvising and using one's imagination. The more that players put into such games, the more rewarding the experience. Rules and dice only need to be used when one wants to insert some unpredictability into the storyline, in order to push the plot forward.

In the end, it may come down to staff preference. Regardless of what game is chosen, one should try the game with family, friends or staff first. Each experience will be a learning experience, revealing what the library is able to support, and what patrons want. Only by considering these factors can any RPG be considered a good fit for a particular library's programming and collections.

Libraries that focus on collecting only the most popular RPGs, or a large number of RPGs, may miss the point if they spend a comparably small amount of time on programming. To do so would result in disconnect, where the library doesn't provide the support required by patrons in order to fully enjoy these collections. A library may have a successful RPG program on the basis of one game. 


\section{Conclusion}

There are many RPGs to choose from in the fantasy genre alone. Publication and sales models for these games can incorporate print, free or purchasable PDFs, print-on-demand, boxed sets, and subscriptions. The publication process may involve peer-review, Open Access, and attempted licensed restrictions for third-party publishers. Any of the RPGs mentioned in this article can be played with the purchase of three or fewer rulebooks. Additional content may be purchased in the form of published adventures and supplements, or may be left to the collective imagination and creativity of the gamers. Free, downloadable 'rules-light' RPGs are an ideal choice for libraries, as they focus on storyline over rules. Libraries should avoid purchasing PDF versions of RPG products due to copyright restrictions. Libraries making informed RPG purchase decisions are more assured of succeeding in RPG programming endeavors, and of having their RPG collections used.

\section{Notes}

[1] "Azor Lok: Ian's Library Gaming and RPG/D\&D World Development Blog", available at http://zardok.wordpress.com (accessed 21 Jan 2011)

[2] "Paizo Help/FAQ", available at http://paizo.com/paizo/faq (accessed 20 Feb 2011)

[3] "Note about printing pdfs", available at http://www.swordsandwizardry.com/?p=174

(accessed 24 Jan 2011)

[4] "An Important Notice Regarding Wizards of the Coast PDFs", email from

customer.service@paizo.com (received 6 April 2009)

[5] "Open Game License: Frequently Asked Questions" available at

http://www.wizards.com/default.asp?x=d20/oglfaq/20040123f (accessed 17 Sept 2010)

[6] "The Dungeons \& Dragons 4th Edition Game System License" available at

http://www.wizards.com/default.asp?x=d20/welcome (accessed 17 Sept 2010)

[7] "Paizo Publishing, LLC Pathfinder ${ }^{\circledR}$ Roleplaying Game Compatibility License", available at http://paizo.com/pathfinderRPG/compatibility (accessed 16 Sept 2010)

[8] "Retro-Clones", available at http://www.retroroleplaying.com/content/retro-clones

(accessed 21 Sept 2010)

[9] "Microlite20: The smallest thing in d20 gaming", available at http://microlite20.net/

(accessed 24 Sept 2010)

[10] http://www.microlite20.net/node/8 (accessed 24 Sept 2010)

[11] "RetroRoleplaying: Microlite74 \& Other Old School Tabletop Roleplaying Games", available at http://www.retroroleplaying.com/ (accessed 27 Sept 2010)

[12] "Dungeon Crawl Classics: Role Playing Game (OGL)", available at

http://www.goodman-games.com/5070preview.html (accessed 24 Jan 2011)

[13] "Goodman Games: Forums: DCC RPG", available at http://www.goodman-

games.com/forums/viewforum.php?f=60 (accessed 9 March 2011)

[14] "Dungeon Crawl Classics", available at http://www.goodman-

games.com/dungeoncrawlclassics.html (accessed 26 Jan 2011)

[15] "Dungeon Crawl Classics Subscription Form", available at http://www.goodman-

games.com/downloads/DCCSubscriptionForm.pdf (accessed 24 Jan 2011)

[16] "Tunnels \& Trolls 7.5 Edition Box Set", available at

http://fierydragon.com/dragonsbreath/?p=249 (accessed 26 Jan 2011)

[17] "Steve Jackson Games", available from http://e23.sjgames.com/ (accessed 23 Sept 2010)

[18] "Chaosium Inc.", available at http://catalog.chaosium.com/ (accessed 8 Oct 2010)

[19] "GURPS: Generic Universal RolePlaying System", available at

http://www.sjgames.com/gurps/ (accessed 8 March 2011) 
[20] "Warehouse 23", available at http://www.warehouse23.com/info/gurps.html (accessed 26 Oct 2010)

[21] "GURPS Lite (Fourth Edition)", available at

http://e23.sjgames.com/item.html?id=SJG31-0004 (accessed 26 Oct 2010)

[22] "Strike to Stun: Warhammer Fantasy Roleplay at its best!", available at

http://www.strike-to-stun.net/downloads (accessed 4 Oct 2010)

[23] "Winds of Chaos", available at http://www.windsofchaos.com (accessed 4 Oct 2010)

[24] "Liber Fanatica", available at http://www.liberfanatica.net/ (accessed 4 Oct 2010)

[25] "The Free RPG Blog: Championing free pencil and paper RPG material", available at http://www.thefreerpgblog.com/ (accessed 27 Oct 2010)

[26] "Free RPG Directory", available at http://www.delicious.com/thefreerpgblog (accessed 27 Oct 2010)

[27] "Free RPG Day", available at http://www.freerpgday.com/ (accessed 25 Jan 2010)

[28] "RPGGeek", available at http://www.rpggeek.com/ (accessed 5 May 2011)

\section{References}

Danforth, Liz (2009), "Tabletop role-playing games", available at http://blog.libraryjournal.com/gamesgamersgaming/2009/06/04/tabletop-role-playinggames/ (accessed 16 Dec 2009)

Nicholson, Scott (2010), Everyone Plays at the Library: Creating Great Gaming Experiences for All Ages, Information Today, Medford, NJ.

Snow, Cason (2008), "Dragons in the stacks: an introduction to role-playing games and their value to libraries", Collection Building, 27, 2, 63-70

Snow, Cason (2009), "Tabletop fantasy RPGs: tips for introducing role-playing games in your library", School Library Journal, 55, 1, 24-5

U.S. Copyright Office (Reviewed November 2010), Copyright Registration of Games (FL108), available at http://www.copyright.gov/fls/fl108.html (accessed 2 March 2011) 